\title{
Social media - a disruptive opportunity for science and extension in agriculture?
}

\author{
M.J. CASEY ${ }^{1}$, A. MEIKLE ${ }^{2}$, G.A. KERR ${ }^{3}$ and D.R. STEVENS ${ }^{4}$ \\ ${ }^{I} P G G$ Wrightson Ltd., Private Bag 1961, Dunedin 9054, New Zealand \\ ${ }^{2}$ Beef + Lamb New Zealand, PO Box 390, Oamaru 9444, New Zealand \\ ${ }^{3}$ NZ Agriseeds Ltd., 2547 Old West Coast Road, RD 1 Christchurch, New Zealand \\ ${ }^{4}$ AgResearch Ltd, Invermay Research Centre, Private Bag 50034, Mosgiel, New Zealand \\ mcasey@pggwrightson.co.nz
}

\begin{abstract}
The use of social media is increasing and provides an opportunity compared to 'traditional' media. Advances in cloud computing and smartphones have increased the ability to utilise different forms of social interaction. Are farmers and rural businesses realising this opportunity? The engagement of the agricultural community in social media was investigated using an online survey of email recipients of the New Zealand Grassland Association and Beef + Lamb New Zealand to understand their use of computing hardware and social media use. Case studies of recent social media use by Beef + Lamb New Zealand, NZ Agriseeds Ltd and a Deer Industry research uptake project are documented. Responses of 209 survey respondents identified $82 \%$ of users with two or more devices, while $100 \%$ used email regularly and approximately $95 \%$ accessed websites on a daily or weekly basis. Regular Facebook use averaged approximately $50 \%$ in the agribusiness and research communities, though this was only $30 \%$ in the farming community. Other social media platform use, such as Twitter, YouTube and Linkedin, was lower. Regular mobile apps use was highest in the agribusiness $(60 \%)$ while this was lower in farming and research communities $(30 \%)$. The case studies highlighted the development of new social networks using Facebook and Twitter as the underlying opportunity for future engagement in agriculture, while websites, mobile apps and YouTube have the capacity to house resources for interrogative learning and support. Resources need to be allocated to ensure the power of these platforms can be harnessed for commerce and practice change.
\end{abstract}

Keywords: social media, survey, agriculture, interrogative learning, extension, adoption, social networks

\section{Key learnings}

- The opportunity to create alternate communities of interest via social media is already here as evidenced by the uptake of the smartphone which enabling farmers to access information during their workday

- The on-line environment provides a new opportunity as a digital blended learning tool to create one to one extension experiences for adoption using websites, skype, webinars, Facebook, Instagram and Twitter to share information, conversations and more

- While social media enables the mass distribution of information at no cost and everyone has equal access to the tools, resourcing must be shifted to providing content, maintaining relevance and credibility, and social network creation.

\section{Introduction}

The use of social media is rising (Newman et al. 2015) and provides an opportunity for networking, extension and adoption, for example, compared to 'traditional' media. Advances in cloud computing and smartphones have increased the ability to utilise different forms of social interaction. Are farmers and rural businesses realising this opportunity?

The term social media covers a wide range of technologies that have developed out of the internet. As the internet continues to mature the term Web 2.0 describes development towards websites that emphasise user-generated content, usability, and interoperability. This has shifted the internet from passive (websites holding information) to active, connecting people and allowing them to contribute to, as well as consume, information.

Social media technologies were available in the early 1990s but weren't popular because there were fewer computers, less internet availability and more difficult platforms which limited use to early technology adopters. However, the increase of mobile computing in the early 2000s promoted the first widely used social media platforms. For example, Facebook began as a social media platform in 2004, Twitter in 2006, ResearchGate in 2008 and Instagram in 2010.

Disruptive technologies are affecting many industries and have altered what is possible. Christensen (1997) defined a disruptive technology as one that displaces an established technology and shakes up the industry, or a ground-breaking product that creates a completely new industry. Traditional or sustaining technology relies on incremental improvement over time to an already established technology, whereas disruptive technology may lack refinement or have performance problems because it is new, appeals to a limited audience and may 
not yet have a proven practical application.

In addition, disruptive technologies may be ignored until the technology matures, and the audience and market share grow and threaten the status quo. Some examples of disruptive technologies include the digital camera (replacing film), email (replacing letters and impacting on the postal services), and smartphones largely replacing cell phones, cameras, calculators and GPS devices. Examples are numerous and new challenges surface every day with this fast changing technology.

So how is the agricultural community recognising and responding to these disruptive technologies? There has been little research into social media use in New Zealand agriculture. This paper will present preliminary data on internet and social media use in agriculture through surveying potential users and describing case study examples. The key objective is to gain some understanding of social media, how it has been used so far and to consider its future potential.

\section{Methods}

\section{Social media survey}

A survey was developed to gather information on how and why people in agricultural fields were using the internet and social media. The intended participants were farmers, agribusiness, researchers, consultants and others working in primary industries across New Zealand. The survey was sent to respondents via the New Zealand Grassland Association (NZGA) email database (914 members).

The survey was sent out once (October 2015) and a reminder sent the following week. The survey remained open but the data were downloaded and analysed after 20 days. Distribution was limited to email rather than using a range of social media channels to reduce the chance of biasing the respondents towards those more likely to use newer forms of social media.

Reported in this paper are the survey questions asked about demographics, device use (hardware and applications used) as well as past and current use of smartphones. The survey asked respondents about personal as well as business use but only business use is reported here. The survey results indicated a wider personal use of devices across all demographics and this is thought to be mainly due to more applications available to be used and more exposure to them. The results are reported as means.

\section{Social media case studies in New Zealand}

The three case studies presented describe different approaches and include a farmer levy organisation (Beef+Lamb NZ), agribusiness (Agriseeds Ltd) and a research focus (extension to Deer Industry Focus farmers).

The case studies document which social media

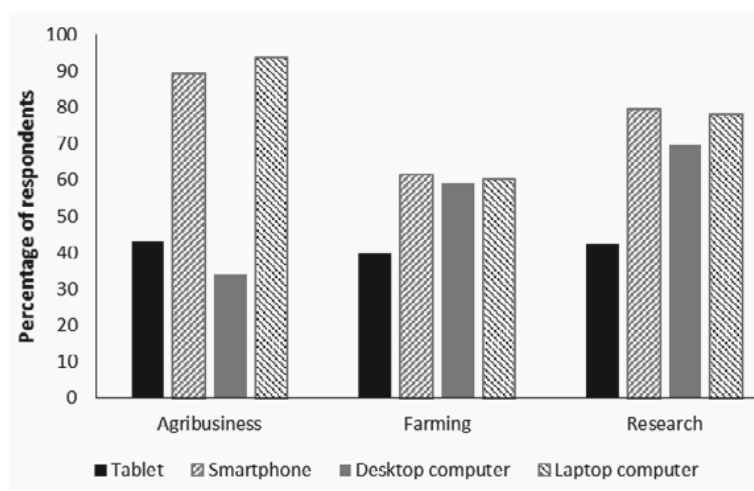

Figure 1 Device use in the agribusiness, farming, and research communities responding to an on-line survey in October 2015.

platforms were used, how they were used and any key lessons observed to date.

\section{Results}

\section{Social media survey results}

After the 20 days 213 people had responded and 202 completed the survey. This is a response rate of $\sim 22 \%$.

The age distribution was skewed towards those over 50 years, with $57 \%$ in the two older age brackets (Table 1). The red meat sector made up nearly $50 \%$ of the respondents, while the dairy sector made up $27 \%$, and arable $10 \%$. Those responding as "others" included people who worked across the sectors, whereas for affiliation of respondents they identified with various related agricultural industries such as consulting, accounting and veterinarians. The "Other" group was combined with Agribusiness for further analysis.

The gender distribution was male $(68.6 \%)$ and female (31.4\%). They were located across all the regions apart from the West Coast of the South Island. The majority of the respondents were from main centres aligned with agricultural research (Waikato 17.3\%; Manawatu 10.9\%; Canterbury $22.8 \%$; Otago $11.9 \%$ ), however, responses also came from diverse regions such as Northland (5.9\%), Bay of Plenty (6.9\%) and Southland (3.9\%).

Laptops and smartphones were both high use devices with desktop computers at approximately $75 \%$ of the rate of use of laptop and smartphones (Figure 1). Tablets were used less, however, $15 \%$ of users were using all

Table 1 Survey demographics.

\begin{tabular}{|c|c|c|c|c|c|}
\hline Age & $\%$ & Sector & $\%$ & Affiliation & $\%$ (no.) \\
\hline $15-30$ & 13 & Red Meat & 47 & Agribusiness & $39(55)$ \\
\hline $31-40$ & 12 & Dairy & 27 & Farming & $27(78)$ \\
\hline $41-50$ & 18 & Arable & 10 & Research & $29(59)$ \\
\hline $51-60$ & 30 & Forestry & 0 & Other & $5(10)$ \\
\hline $60+$ & 27 & Other & 16 & & \\
\hline
\end{tabular}



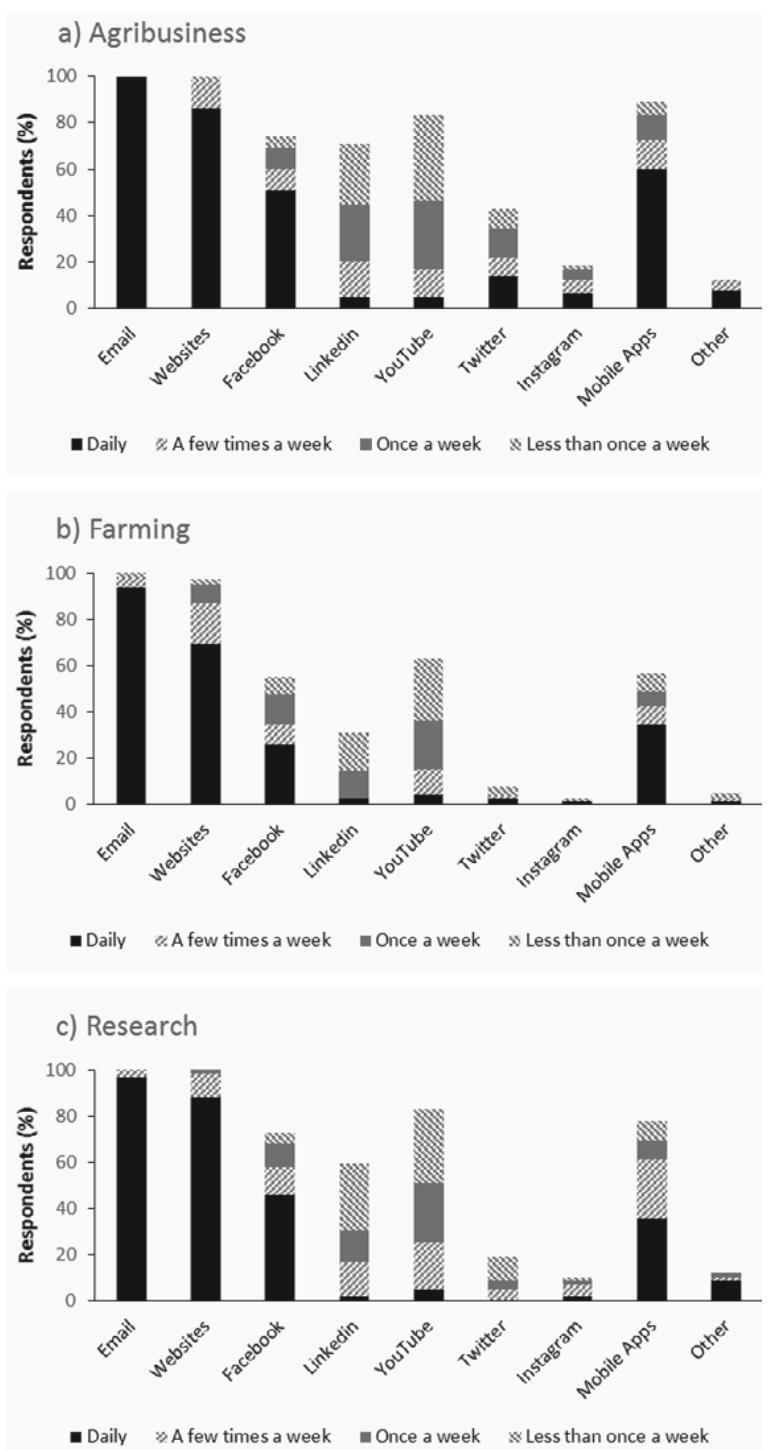

Figure 2 Social media applications used by the a) agribusiness, b) farming and c) research communities answering an on-line survey in October 2015 .

four devices, and $40 \%$ were using three devices, $30 \%$ two devices and $15 \%$ only one device.

Of the 191 respondents to the question "Do you use a smartphone", 52\% were users in 2012 and $30 \%$ had added a smart phone since, while $18 \%$ still aren't using one.

When analysed by community from 2012 to 2015 , the use of smartphones by agribusiness rose from 75 to $96 \%$ while in the farming community it doubled from 31 to $62 \%$, and in research it increased from 41 to $86 \%$.

When asked about the use of various social media applications (Figure 2) all communities used email daily or several times a week, as would be expected of a community of on-line users. Website use also approached $100 \%$ throughout the agribusiness, farming and research communities. The agribusiness and research communities had made similar use of Facebook with approximately $50 \%$ using it regularly (daily or a few times a week), while those identified as farming used Facebook with less regularity, though was still at approximately $30 \%$ using it daily or a few times a week.

LinkedIn and YouTube were used widely but less frequently than email, websites and Facebook (Figure 2 ). The farming community were less likely to use LinkedIn. Twitter use (Figure 2) in the agribusiness community was higher than the other two communities, and used more frequently. However, those farmers that were using Twitter were using it regularly and more frequently than research.

The agribusiness sector used mobile apps the most (Figure 2), and most frequently, with daily use by approximately $60 \%$ of respondents, compared with approximately $30 \%$ in the farming and research communities.

ResearchGate was the most commonly mentioned other application, closely followed by weather based applications.

An interaction between age and mobile app use was observed. In the two age groups representing respondents under the age of 41 , frequent engagement with mobile apps was $84 \%$ (Table 2). This use declined in the 41-50 age group with an increase in infrequent use. In the 51-60 age group the number of respondents reporting no use ("Never") showed a marked increase to $30 \%$. This remained high in the $61+$ group, and infrequent use also rose in this group.

A Wordle analysis was used to indicate the current most frequently used platforms identified by all the respondents (Figure 3). This identified Email, newsletters and websites as the most used (as designated by font size in Figure 3). Weather apps and farm management systems (Farmax, FarmIQ, Overseer, MINDA and CashManager) were also identified as useful but many other services and platforms were mentioned.

Table 2 An interaction between age and mobile app use in respondents answering an on-line survey in October 2015. (Number of respondents in each category reported).

\begin{tabular}{|c|c|c|c|c|c|c|}
\hline & \multicolumn{6}{|c|}{ Age group (years) } \\
\hline & $15-30$ & $31-40$ & $41-50$ & $51-60$ & $61+$ & Total \\
\hline $\begin{array}{l}\text { Frequent (daily or } \\
\text { few times a week) }\end{array}$ & 23 & 18 & 26 & 35 & 14 & 116 \\
\hline $\begin{array}{l}\text { Infrequent (weekly } \\
\text { or monthly) }\end{array}$ & 1 & 4 & 8 & 6 & 13 & 32 \\
\hline Never & 1 & 2 & 3 & 18 & 19 & 43 \\
\hline Total & 25 & 24 & 37 & 59 & 46 & 191 \\
\hline
\end{tabular}




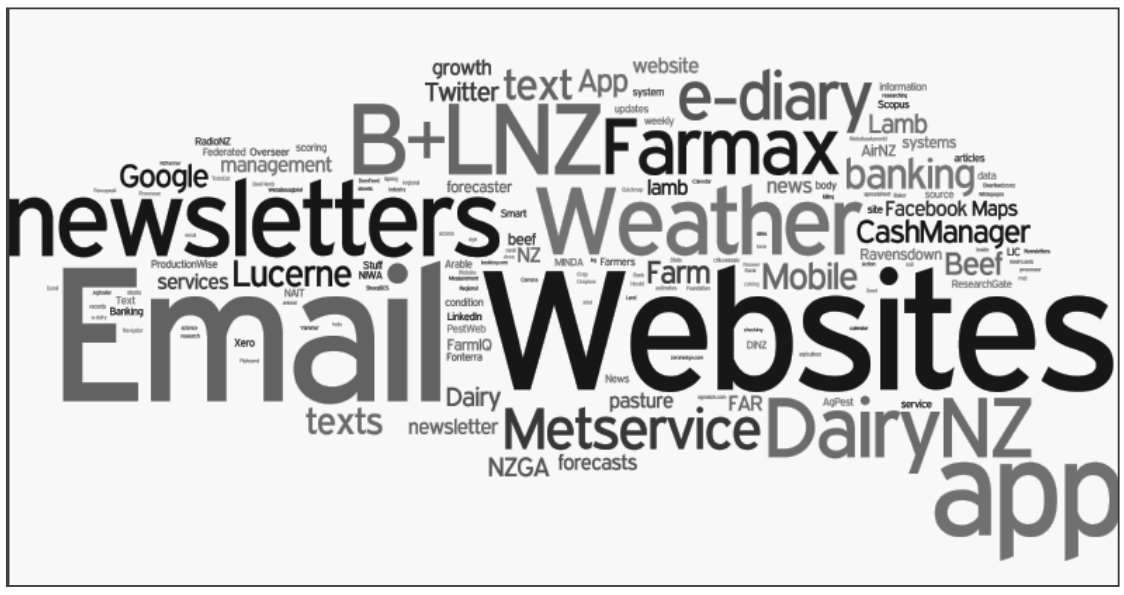

Figure 3

A word cloud depiction of the applications most frequently used by the respondents of an online survey in October 2015.

\section{Social media case studies}

Beef+Lamb NZ case study

Beef + Lamb NZ (B+LNZ) is a farmer levy organisation that has developed their social media presence over the past 5 years. They began their social communication with farmers through email and the e-diary via their extension managers. The beeflambnz.com website is the information and resource hub while social media (email, Facebook, YouTube and Twitter) provides the opportunity to bring people to the site. They have tested other channels such as text messaging, LinkedIn, Instagram and Pinterest. $\mathrm{B}+\mathrm{LNZ}$ recognises the potential for these tools to allow more targeted and personalised extension, to complement the more traditional media. $\mathrm{B}+\mathrm{LNZ}$ has regionalised its activity enabling staff to interact using social media on local issues $-\mathrm{B}+\mathrm{LNZ}$ use texting for the Lucerne Management Text Service and AgPest. Each has a set schedule of predetermined messages throughout the year. These services also provide the opportunity to respond to immediate issues (for example local outbreaks of aphids), can be targeted to a specific region, and can also provide answers to user's questions. These answers are then often included in the general messages. The ability to provide specialist advice in real time has led to very high levels of farmer engagement and satisfaction reflected in the high number of farmers signing up to these service as well as positive responses to evaluations done by $\mathrm{B}+\mathrm{LNZ}$. Texts can also be automatically uploaded to a linked Twitter account, reaching another audience and preserving messages in a 'library' for reference.

It is assumed that Facebook followers of B+LNZ's page are younger than average. Therefore a key activity on Facebook has been to promote opportunities for younger farmers such as B+LNZ's Scholarships. Facebook advertising of events is also likely to target a younger farmer profile.

Women's networks are also targeted through Facebook. For example, B+LNZ and Agri-Women's
Development Trust provide a series of "Understanding Your Farm Business" workshops for women who wished to increase their role and responsibilities in their farm businesses. A course in Central Otago was oversubscribed after 1 hour of a member sharing the notice on the local rural women's Facebook group.

$\mathrm{B}+\mathrm{LNZ}$ staff is encouraged to have active Twitter accounts, and to use them in two ways. Firstly, to link to $\mathrm{B}+\mathrm{LNZ}$ information that is timely and valuable. Images of tables and graphs are particularly valuable here and enable the author to circumvent the 140 character per tweet limit. Secondly, to regularly tweet images and comments from events such as field-days. This engages an additional audience, and with the use of hashtags (\#) provides an informal summary for later perusal.

\section{NZ Agriseeds case study}

NZ Agriseeds use Twitter and Facebook as part of their marketing and communication plan. They have a coordinated and linked social media strategy across Twitter, Facebook, their website and their traditional print media marketing platforms. They put information on their website, and are using Twitter (through followers) and a Facebook page (through those that Like us) as the engagement back to content. Their social media use has a planned timetable similar to a marketing philosophy for a product launch.

NZ Agriseeds pasture systems specialist has recently begun to use Twitter in his extension role. The value of Twitter as a microblogging network using 140 characters or less is that it is not limited to one platform as it can be delivered and accessed via smartphones, tablets and computers.

The focus of messages is always pasture and photographs are utilised to reinforce the message. For example, there is "an informal NZ Ugliest Pasture competition" on Twitter - a competition you don't want to win..." using the hashtag "\#ugliestpasture". To help with NZ Agriseeds focus on pasture renewal 
and of course, improved seed sales, there is also a "\#superiorpasture". The use of hashtags provides a link or common theme to messages that can be searched within Twitter.

NZ Agriseeds have noticed that they now have quite different groups of people engaging in different media channels. The print media is still very popular, but circulation of some publications seems to be dropping, particularly to the younger generation. Similarly, Twitter and Facebook audiences seem to be different. Twitter users engage more during the day, as an ongoing conversation, which may indicate smartphone use and the ability to make short timely comments. Facebook engagement seems to mostly happen in the evenings, indicating greater use of other devices (tablets/ laptops /computers).

\section{Deer Industry case study}

The 'After the Field Day' Sustainable Farming Fund programme within the Deer Industry aimed to better deliver the field day messages. This included developing a website to hold the information, and providing the latest research in an easily read format specifically targeting farmers questions or misinformation.

One of the objectives of this programme was to look at all the social media opportunities and to understand and use the tools and platforms that were becoming available. This started in 2011 when websites, email, texting and Facebook were the most common tools and smartphones were yet to become prevalent.

The 'After the Field day' project team began by developing a website to host resources including key message fact sheets and email and text messages to distribute messages.

The key learnings as a result included:

- the value of the website as a repository for information

- text messages to a distribution list is simple, cost effective and can provide timely information such as field day reminders or links to further resources

- the potential to link information across all platforms - website, text message, email, online newsletter

- always use embedded hyperlinks to encourage readers to access further information.

As the project neared completion it was realised that technology had moved rapidly and new platforms such as Twitter and mobile apps were becoming more important, especially as smartphone use expanded. The project then developed two mobile apps for farmers to pilot an approach to use the smartphone to enable decision making.

The question arose - was it possible to design a simple tool that embedded science into a tool for learning, management and extension? The first app was designed to answer a common question farmers asked at field days - "how do I know how much to feed my deer?"
After experimenting with many apps, both agricultural and others, development focussed on the following features of the best apps:

- they are simple to use

- they don't need to be connected to the internet to function

- they do one thing well

- they are intuitive - no instructions or very simple instructions

- they don't have a large number of steps or screens.

The key objective was to enable ready access to, and the use of, current research and best practice feed management embedded in a simple tool.

The first app (DeerFeed Intake, www.deerfeed.co.nz) used current nutrition models to predict the intake requirements for optimal growth for hinds or weaners based on current liveweight, liveweight target and time of year. The app was promoted in the deer industry through the industry website, traditional media, and email newsletters and at Focus farms and workshops. This prompted demand from users for the second app (DeerFeed Allocation, www.deerfeed.co.nz) which allows farmers to allocate the feed they have available.

The smaller number of farmers in the deer industry and good levels of interaction with researchers and veterinarians meant that the apps were widely distributed and promoted to willing users.

The social media platforms and the key activities undertaken in each of the case studies is summarised in Table 3 demonstrating the range of engagement.

\section{Discussion}

The results of the survey show that the agriculture community is well-connected across farming, agribusiness and research with $85 \%$ using 2 or more devices. Similarly $82 \%$ of respondents reported using a smartphone, an increase of $30 \%$ since 2012 . Therefore, it could be inferred that for many respondents the second device is a smartphone. This level of use matches the expectation by Horizon Research (2014) that by September $201580 \%$ of New Zealand adults will have a smartphone. Their survey showed that farm owners and managers were the largest group intending to get a smartphone by September 2015 (56.5\% compared to $10.4 \%$ for adults overall). However, our survey showed farmers were lower than this metric with a $31 \%$ increase over 3 years.

The mean age of the survey respondents was 53 years, a reflection of general population dynamics rather than an indication of the ageing of the rural population (Lissaman et al. 2013).

Use of computers (laptops and desktops) is well established (near 100\%) in agricultural communities and the use of email and websites is correspondingly high. This can be compared to recent New Zealand 
data (Colmar Brunton Survey; MYOB Oct 2014) which reported that email and online banking are the most commonly used online services. However, they also showed that the majority of small and mediumsized businesses in the primary sector are still to move online, with $68 \%$ reporting no online presence. Just $14 \%$ have a website and only $4 \%$ operate both a social media site and website compared to retail and hospitality ( $25 \%$ website or $29 \%$ both) or finance and insurance (30\% and 19\%). These data highlights the simple opportunities that can be overlooked to engage with the agriculture community via email and an online presence. This includes research and extension as well as business opportunities.

The disruptive social media technologies utilise different channels and the survey aimed to see how the agricultural community was adopting these. The survey asked respondents about their use of a few dominant channels, specifically Facebook, LinkedIn, YouTube, Twitter, Instagram and more generically, mobile apps. The results differed for each sector with the agribusiness and research communities using Facebook (approx. 60\%) and mobile apps regularly followed by YouTube and LinkedIn. Farmers were less likely to use these channels, but still those that did, used Facebook ( $20 \%$ daily, $40 \%$ at least once a week), LinkedIn and mobile apps. In New Zealand 2.5 million people access Facebook every month and of those 1.9 million access Facebook every day or $\sim 45 \%$ of the population (Facebook 2015). By comparison Australian research (McCue 2014) suggested that $15 \%$ of growers were considering using Facebook, lower than New Zealand

Table 3 The range of social media platforms used and the key activities undertaken in three case studies in New Zealand agriculture.

\begin{tabular}{llll}
\hline $\begin{array}{l}\text { Social media } \\
\text { platform }\end{array}$ & \multicolumn{2}{c}{ Key activities } & \\
\cline { 2 - 3 } & Beef+Lamb NZ & NZAgriseeds & Deer SFF \\
\hline Website & www.beeflambnz.com & www.agriseeds.co.nz & www.deerfarming.co.nz \\
& & www.deernz.org.nz \\
\hline Email & Farmer e-diary (regional focus) & Email newsletters \\
\hline Text messages & Lucerne management text service (@BLNZ_- & Notification of field days (50 - \\
& Lucerne 556 followers; 29 Nov 2015) & 80 subscribers) \\
& @AgPestNZ text service (238 followers; 29 Nov & $\begin{array}{l}\text { Dissemination of relevant } \\
\text { information (use of hyperlinks } \\
\text { and images) }\end{array}$
\end{tabular}

\begin{tabular}{lll}
\hline Twitter & $\begin{array}{l}\text { Dissemination of relevant information (use of } \\
\text { hyperlinks and images) } \\
\text { Tweets from B+LNZ events } \\
\text { Communication with wider audience of farmers } \\
\text { and consumers }\end{array}$ & $\begin{array}{l}\text { Community of interest - } \\
\text { marketing and communication } \\
\text { (@GrahamAgriseeds 657 } \\
\text { followers; 29 Nov 2015) }\end{array}$ \\
\hline Tacebook & Womet young farmers - B+LNZ scholarships & Marketing and communication \\
& Linking to similar pages to promote events & \\
\hline
\end{tabular}

\begin{tabular}{lll}
\hline Mobile Apps & & DeerFeed intake \\
& & DeerFeed allocation \\
\hline YouTube & Technical videos (body condition scoring sheep) & \\
\hline Linkedln & Promotion & NZ Agriseeds connection with \\
\hline Blogs & Pushing the Boundaries - research blog to & \\
\hline
\end{tabular}


farmers current use of $20 \%$ using it on a daily basis and $40 \%$ at least once week. It is important to recognise that the current survey data are for an adult population (compared to the NZ Facebook data above) and considering the interaction between the ages of those who responded and web-based application use, then our reported use of this platform is remarkably high.

This is also highlighted in the use of these platforms by researchers. Van Noorden (2014) surveyed thousands of researchers to find out how they use social networks and other services and in the science and engineering field the following sites were visited regularly; Google Scholar (60\% of the respondents), ResearchGate (48\%), LinkedIn (41\%) and Facebook $(38 \%)$. By comparison our respondents use was higher with Facebook (45\%) and LinkedIn (55\%) compared to international researchers, possibly due to a greater need to connect with the wider research community.

In general our New Zealand agribusiness and research community is highly connected and what they are using is influenced by their role therefore Email and websites are the most used platforms. For example, Van Noorden (2014) determined the researchers activities ranged from curiosity only to posting research papers, discovering recommended papers, commenting on and following research discussions and connecting with peers.

The farming community is less connected and the comments in the survey identified that cellular network and internet access was more limiting for them. As a result the farming community also wanted more applications for smartphones that worked offline to enable them to access the useful tools. An observation from $\mathrm{B}+\mathrm{LNZ}$ linked farmer online media and tools use to available time, rather than connection speed, data caps or hardware. While these can still be an obstacle, B+LNZ now targets delivery to smartphones and tablets which can be used more easily during the working day.

It is interesting to note that approximately $30 \%$ of the agribusiness community used Twitter more than once a week. Of the farmers who used Twitter (10\%) it appeared that half of them used it more than once a week. This appears to be a platform where farmers that use it are actively engaged and, therefore, provides further opportunities.

The definition of social media as tools that allow people to create, share or exchange ideas, pictures or information (Shirky 2008) implies the development of virtual networks of connected users (Fuchs 2010). Rangaswami (2012) commented in a blog post that 'social is the plural of personal' and that here social is not a feature or a product but instead has a role in bringing human relationships back into business, including how and why people conduct business. Extension practices frequently used in New Zealand encompass this social aspect of extension and adoption and include monitor or focus farms, discussion groups, workshops and field days. The case studies show the beginning of 'new' agricultural networks developing through platforms such as Twitter (\#ugliestpasture), lucerne text service or B+LNZ Facebook groups (Table 3).

The case studies (Table 3 ) highlight a common theme of using the website as a repository for information and using other forms of social media to engage the audience with the information. This includes embedding hyperlinks, images and data in to email newsletters, text messages, Twitter and Facebook posts. This immediacy of access to information was identified as a positive attribute to provide farmers with the opportunity to search for answers to questions that are relevant to their business and in a timely manner. This process may be described as interrogative learning where users are actively involved in the hunt for information that is specific and immediate to resolve urgent issues.

Social media technologies also provide an opportunity to reach a new audience, such as younger people, nonfarming partners, women, students, agribusiness and research who may be less likely to access traditional media or extension activities. The opportunity to increase engagement and access to information using what may be considered 'older' platforms such as texting and email shouldn't be overlooked as these are still the most utilised and, therefore, the easiest to use, by both those that access information, and the providers of the information.

There are both benefits and risks to using social media. It can be a distraction and end up diluting the effectiveness of any messages if it is not planned properly and both the time and the budget allowed for. Social media provides access to an immense store of knowledge and ideas from a range of sources. One of the criticisms is around the reliability of the information and whether it can be trusted. To reduce this any use of social media requires that the users develop a level of authority to be effective and this encapsulates both trust and the credibility of any information. There are also risks to a reliance on social media over traditional engagement and these include permanency of the information, privacy and ownership of content. Some social media messages can be ephemeral or simply lost in the noise of the mass of online traffic.

The low cost of both accessing and distributing information was identified by the case studies as a positive. Effective digital communication, like traditional media, still has a significant cost in time, however, as no paper, printing or physical distribution are required distribution costs are negligible.

A key opportunity, however, is the viral nature of social media, the opportunity to 'share' and repost enables messages to spread quickly. Similarly 
conversations can also be global. However, negative messages spread just as quickly, though B+LNZ use Twitter as a medium for rapid response when this occurs. Both B+LNZ and NZ Agriseeds have used the viral nature to enable direct interaction with people of influence and this can be seen across the conversations (hashtags) in Twitter.

The provision of tools for mobile use was tested in the DeerFeed apps. This is an area where more is being requested by users (Figure 3). Engagement with this need has been tentative as traditional agencies must first understand the needs of the end-user and then design tools in new ways.

\section{Conclusions}

The opportunity to create alternate communities of interest via social media is already available as evidenced by the uptake of the smartphone which enables farmers, particularly, to access information during their workday.

The survey provided an insight into the welldeveloped hardware platform that is available throughout agriculture. Younger community members are more engaged, especially with mobile apps. Offline compatibility is required for tools use, but many farmers and agribusiness members are well connected and willing to be part of wider social networks using social media.

Social media networks are effective at increasing participation, making it easier to join or participate with the case studies highlighting the many opportunities of the internet and social media.

In addition, the opportunity should be considered as a digital blended learning tool or as an online yet one to one space for extension and adoption using websites, skype, webinars, Facebook, Instagram and Twitter to share information, conversations, photographs and more. While social media enables the mass distribution of information at no cost, resources must be shifted to providing content and maintaining relevance and credibility.

With the rise of the internet everyone is used to instant access to a huge source of information and are becoming a 'now' generation. Farmers may sit down at $8 \mathrm{pm}$ to find some answers about pasture - and expect to have answers by $8.30 \mathrm{pm}$ - whereas just 10 years ago it would have been more likely a phone call to the local retailer or company representative during business hours. The future? Who knows; one thing that is happening is that change is ever faster.

\section{ACKNOWLEDGEMENTS}

Many thanks to those who answered the on-line survey, assisted with the case studies, and to Deer Industry NZ and the Ministry of Primary Industries for funding the After the Field day project through the Sustainable Farming Fund.

\section{REFERENCES}

Armstrong, J.; Franklin, T.F. 2008. A review of current and developing international practice in the use of social networking (Web 2.0) in higher education. Accessed Sept 2015. http://franklin-consulting. co.uk/publications.html

Christensen, C.M. 1997. The innovator's dilemma. Publ. Harper Collins, 2003.

Colmar Brunton Survey; MYOB Oct 2014.

Facebook usage in New Zealand, May 2015. Accessed Oct 21 2015. http://www.firstdigital.co.nz/ blog/2014/09/10/facebook-demographics-newzealand-age-distribution-gender/\#Facebook 2009

Fuchs, C. 2010. Social media and networking: concepts, methodologies, tools, and applications. Ed. DeMarco, A. Publ. IGI Global.

Horizon Poll. 2014. Adult smartphone ownership will hit 79\% within year. Accessed Sept 12, 2015. https:// www.horizonpoll.co.nz/page/388/adult-smartphoneownership-will-hit-79-within-

Lissaman, W.; Rowarth, J.R.; Casey, M.J. 2013. Innovation and technology uptake on farm. Proceedings of the New Zealand Grassland Association 75: 27-32.

McCue, T. 2014. Navigating the app minefield. Accessed Sept 2015. http://www.enablingchangeand innovation.com.au/wp-content/uploads/2014/03/ Navigating-the-App-Minefield.pdf

Newman, N.; Levy, D.A.L.; Nielsen, R.K. 2015. Reuters Institute Digital News Report 2015; Tracking the future of news. Reuters Institute for the Study of Journalism, Department of Politics and International Relations, University of Oxford.

Rangaswami J.P. 2012. Accessed Sept 2015. http:// confusedofcalcutta.com/2012/11/02/plural-ofpersonal-is-social/

Shirky, C. 2008. Here comes everybody: how digital networks transform our ability to gather and cooperate. Publ. Penguin Press, New York.

Van Noorden, R. 2014. Online collaboration: Scientists and the social network. Accessed Oct 21 2015. Nature. http://www.nature.com/news/online-collaborationscientists-and-the-social-network-1.15711 